\title{
Retalho de omento: uma alternativa em cirurgia reparadora da parede torácica
}

\author{
Omentum flap: an alternative in reconstructive surgery of chest wall
}

\author{
Francisco Marcelo de \\ Oliveira Tavares ${ }^{1}$ \\ Cristina Maria Gomes Gil \\ De Menezes ${ }^{2}$ \\ Marcus Vinícius Alfano \\ $\mathrm{MOSCOZO}^{3}$ \\ Gustavo Robson SAntos \\ XAVIER $^{4}$ \\ Gustavo Medeiros de \\ OLIVEIRA $^{4}$ \\ Marcos Antônio Paiva \\ AMORIM JÚNIOR \\ WiLSON NunES DA GAMA ${ }^{1}$
}

Trabalho realizado no Hospital São Rafael, Salvador, BA, Brasil.

Artigo submetido no SGP (Sistema de Gestão de

Publicações) da RBCP.

Artigo recebido: $24 / 8 / 2009$

Artigo aceito: 1/10/2009

\begin{abstract}
RESUMO
Introdução: Diversas doenças podem acometer a parede torácica e sua evolução, eventualmente, pode levar a sequelas seriamente deformantes. Dentre as mais comuns citamos tumores de partes moles e ósseos, metástases, infecções como as mediastinites e fasceítes necrotizantes. Diversas formas de reconstrução da parede torácica podem ser empregadas para a reparação de defeitos após ressecções ou desbridamentos, dentre as quais a reconstrução com retalho de omento e enxerto cutâneo. Apesar de pouco empregada e descrita na literatura, esta tem se mostrado uma boa opção em função de sua fácil execução, rapidez e praticidade, podendo cobrir grandes áreas de parede torácica onde não seria possível a obtenção de retalhos de tamanho satisfatório. Relato do Caso: Este trabalho tem como objetivo fazer uma revisão da literatura a respeito do retalho omental, discorrendo sobre suas indicações, vantagens e desvantagens e relatar a evolução de dois pacientes operados em nosso serviço, submetidos à correção de defeito em parede torácica após a ressecção de tumores filoides de mama localmente avançados utilizando o retalho de omento. Conclusão: A reconstrução com retalho omental e enxerto para a reparação de defeitos após ressecção de tumores, quando bem indicada, mostra-se uma maneira eficaz de reparo da parede torácica, com pobre resultado estético, porém com bom resultado funcional, cumprindo o papel ao qual se propõe.
\end{abstract}

Descritores: Omento. Retalhos Cirúrgicos. Parede Torácica.

\begin{abstract}
Introduction: There are several diseases that can be achieve the chest wall including wall tumor and infections; some of those may lead to the need for reconstruction of its integrity. Among the options of chest wall reconstruction, the omentum flap with skin graft is a valuable choice, especially when other fasciocutaneus or miocutaneus flaps are not available. There are several diseases that can achieve the chest wall, including wall tumors and infections; some of those may lead to the need for reconstruction of its integrity. Among the options of chest wall reconstruction, the omentum flap with skin graft is a valuable choice, especially when other fasciocutaneus, or miocutaneus flaps are not available. Case Report: This article presents two case reports in which the omentum flap with skin graft has been used for reconstruction of the chest wall after massive resections. Conclusion: It is shown that the omentum flap is an easy and effective surgical option for restore the chest wall's cover, despite its poor aesthetical results.
\end{abstract}

Keywords: Omentum. Surgical Flaps. Thoracic Wall.

1. Membro associado Sociedade Brasileira de Cirurgia Plástica (SBCP); Membro do Serviço de Cirurgia Plástica do Hospital São Rafael, Salvador, BA, Brasil.

2. Membro titular da SBCP; Membro titular da Sociedade Brasileira de Microcirurgia; Regente do Serviço de Cirurgia Plástica do Hospital São Rafael, Salvador, BA, Brasil.

3. Membro titular da SBCP; Coordenador do Serviço de Cirurgia Plástica e Residência Médica do Hospital São Rafael, Salvador, BA, Brasil.

4. Médico residente do Hospital São Rafael, Salvador, BA, Brasil. 


\section{INTRODUÇÃO}

A primeira descrição do uso do grande omento como retalho data de 1896, por Drummond e Morrison ${ }^{1}$, na confecção de um shunt porto-sistêmico. Desde então, o uso do epíplon tem sido relatado nas mais variadas situações ao longo dos anos: no tratamento de infecções mediastinais ${ }^{2}$, tratamento do linfedema crônico ${ }^{3,4}$, reconstrução mamária ${ }^{5,6}$, revascularização de extremidades ${ }^{7}$ e como proteção em órgãos a serem irradiados ${ }^{8}$. Seus usos mais descritos em Cirurgia Plástica referem-se à reconstrução mamária associada à colocação de tela e cirurgia reparadora de partes moles, incluindo as paredes torácica e abdominal.

Os tumores filoides correspondem a um grupo de neoplasias da mama caracterizadas histopatologicamente por possuírem tecido estromal abundante e grande hiperplasia, com predominância do componente estromal, o que dá a esses tumores um aspecto microscópico semelhante a folhas (do grego phyllo), de onde vem sua denominação. Sua incidência é pouco frequente $(0,5-1 \%)$, acomete mais a mama esquerda e suas formas malignas, tem por característica serem altamente agressivas localmente e possuírem um elevado índice de recidivas, com prognóstico reservado em formas metastáticas e avançadas.

O objetivo deste trabalho é fazer uma revisão da literatura existente a respeito do retalho omental, discorrendo sobre suas indicações, vantagens e desvantagens e relatar dois casos operados em nosso serviço, onde foi feita correção de defeito em parede torácica após a ressecção de tumores filoides da mama localmente avançados utilizando o retalho de omento e cobertura deste com enxerto de pele.

\section{Anatomia}

O grande omento desenvolve-se por volta do quarto mês de vida intrauterina a partir da bolsa epiplóica, que é originada do mesogástrio dorsal primitivo ${ }^{9,10}$. Em seu crescimento, direciona-se caudalmente em direção à esquerda, onde se funde ao mesocólon transverso, originando-se o grande omento. Quando completada sua organogênese, ele consiste de uma dupla lâmina de peritônio, com suas artérias e veias interpostas entre estes.

O grande omento é irrigado por ramos das artérias e veias gastroepiplóicas direita e esquerda, as quais correm pararelo à grande curvatura do estômago e unem-se no meio deste. Estes ramos são as artérias omentais esquerda, média e direita, oriundas dos vasos gastroepiplóicos direito e esquerdo, respectivamente. A artéria e veia médio omentais surgem no centro do omento, no ponto aproximado da união dos vasos gastroepiplóicos. A artéria omental acessória é um ramo menos importante, que surge da artéria gastroepiplóica direita, próximo à emergência da artéria omental correspondente.

Destacamos, também, os vasos omentais curtos, que emergem ao longo de toda a artéria gastroepiplóca em direção ao omento. Estes vasos correm na porção proximal do epíplon. A artéria médio omental se bifurca distalmente em ramos direito e esquerdo. As anastomoses entre estes vasos forma a arcada vascular do omento.

São descritas cinco variações anatômicas da vascularização epiplóica, dependendo da altura da bifurcação ou ausência da artéria médio omental ${ }^{9}$.

\section{Retalho de Epíplon}

O retalho de epíplon possui versatilidade e características singulares, com emprego possível em diversos tipos de cirurgia reparadora, conforme anteriormente descrito. Devido ao seu tamanho, é possível a cobertura de grandes áreas cruentas quando isto se faz necessário. Seu comprimento possibilita a cobertura de defeitos relativamente distantes de seu pedículo. Ainda que o defeito se encontre distante, é possível ampliar o alcance deste retalho por meio da secção terminal de uma das artérias gastroepiplóicas ou de seus vasos terminais, "abrindo" o avental omental, o que aumenta bastante seu arco de rotação. É preferível proceder à secção da artéria gastroepiplóica esquerda visto que o calibre da artéria direita é discretamente maior ${ }^{9}$. Sua consistência maleável permite a cobertura de áreas irregulares, onde outros retalhos não se moldariam.

Também é possível utilizar o retalho de epíplon com a função de obter volume, como em reconstrução mamária e no combate de infecções como no tratamento de esternotomias infectadas e mediastinites. Devido a este retalho ser amplamente vascularizado, ele é considerado um bom leito receptor para enxertia cutânea, com poucas complicações locais. Sua obtenção é relativamente simples e rápida, apresentando pequeno índice de complicações. Ele pode ser obtido através da via aberta ou laparoscópica, como descrito a seguir: desinserção do cólon ao longo do plano avascular, separação do avental omental do estômago com preservação da arcada gastroepiplóica. Neste momento, avaliamos o alcance do retalho. Caso necessário, optamos pela secção da artéria gastroepiplóica esquerda, pelo motivo já exposto. O omento então é transposto através de túnel que, a depender da cirurgia, pode ser subcutâneo ou transdiafragmático. Neste momento, deve-se evitar compressão ou acotovelamento do retalho, o que pode comprometer sua viabilidade. Procedemos, então, à cobertura da área a ser reparada e fixação com pontos separados de nylon incolor ou vicryl. Retirada do enxerto de pele parcial expandido ou não dos membros inferiores e aposição da pele retirada com fixação com pontos separados de vicryl de rápida absorção.

\section{RELATO DOS CASOS}

\section{Caso 1}

D.M.P, 47 anos, sexo feminino. Sem comorbidades. Nega história familiar de câncer de mama. Procurou o ambulatório 
de mastologia, em agosto 2006, com nódulos localizados em ambas as mamas, sendo que os de maior tamanho localizavam-se em mama esquerda, quadrante superior externo, medindo aproximadamente $6 \times 6 \mathrm{~cm}$. Anteriormente, a paciente já havia sido submetida à exérese de nódulo nesta mesma localização, há dois anos, com diagnóstico histopatológico de fibroadenoma. Foi indicada nova retirada desses nódulos, com os seguintes diagnósticos: mama direita fibroadenoma; mama esquerda - tumor filoide boderline com margens comprometidas.

Foi indicada, então, mastectomia total subcutânea e aposição de prótese expansora temporária. Realizado o procedimento e novo exame histopatológico revelou tumor filoide com margens livres de neoplasia.

A paciente permaneceu sem intercorrências clínicas até que, em janeiro de 2008, no momento da colocação de prótese definitiva, foi observada pequena tumoração palpável na topografia da aréola esquerda. Realizadas troca da prótese e biopsia deste novo nódulo. O exame histopatológico evidenciou novamente tumor com características boderline. A análise imunohistoquímica revelou tumor filoide de potencial biológico incerto. Realizada retirada da lesão e aréola com margens. A partir de então, houve recorrência tumoral agressiva e rápida, em que o tumor atingiu todo o hemitórax esquerdo, regiões infraclavicular e axilar homolateral com grandes áreas ulceradas, sangramento e hiperemia perilesional.

A paciente foi encaminhada à equipe de cirurgia torácica, sendo propostas toracectomia esquerda alargada e reconstrução do defeito com retalho omental e enxertia cutânea com pele, as quais foram realizadas em novembro 2008. O exame histopatológico mostrava peça com margens livres, porém mínimas em alguns segmentos.

A paciente evoluiu sem intercorrências no pós-operatório imediato, com boa integração do enxerto. Cerca de três meses após o procedimento, evoluiu com nova e ainda mais agressiva metástase locorregional, com disseminação tumoral por toda a parede torácica. Encaminhada à oncologia clínica, não compareceu mais ao serviço.

As Figuras 1 a 7 ilustram as principais etapas de atendimento dessa paciente.

\section{Caso 2}

DMA, 56 anos, sexo feminino, tabagista desde os 20 anos de idade. Menarca aos 12 anos, G0P0A0. Tias com história de câncer de mama. Veio à consulta com queixas de nódulo em mama esquerda, em abril de 1995. Há 12 anos, paciente apresentou dois nódulos em mama esquerda de aspecto endurecido, indolor e sem sinais flogísticos, realizada biopsia, com diagnóstico de fibroadenoma. A paciente foi, então, submetida à nodulectomia. Evoluiu no ano seguinte com o aparecimento de múltiplos nódulos em mama esquerda e um nódulo em mama direita, constatado tumor filoide e

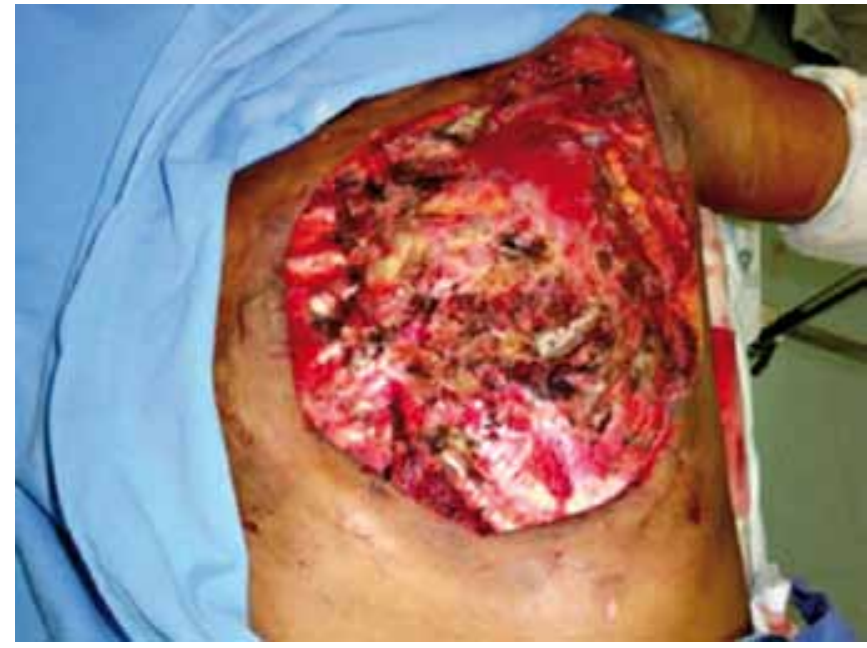

Figura 1-Caso 1: Defeito após toracectomia esquerda alargada.

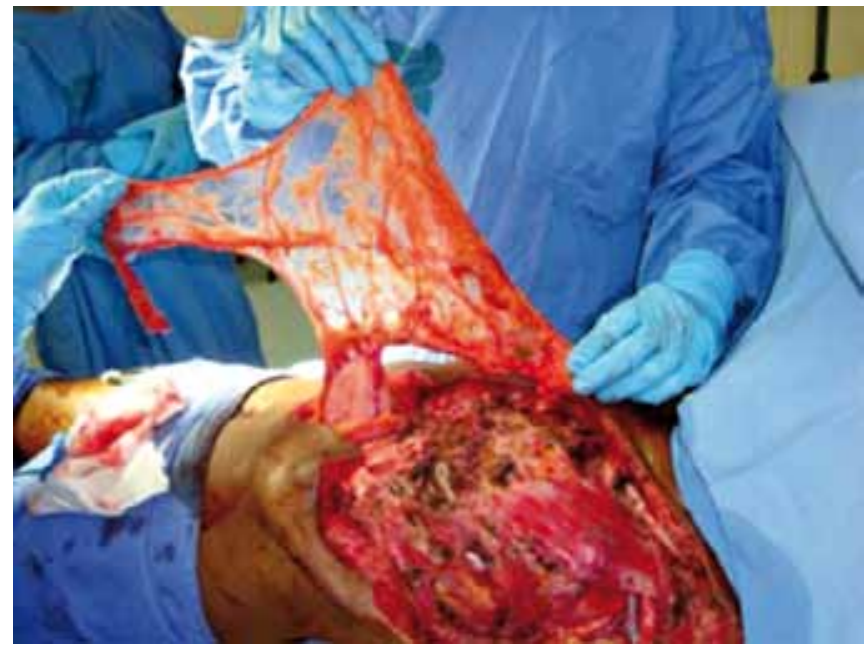

Figura 2-Caso 1: Mobilização do epíplon pediculado em ambas artérias gastroepiplóicas.

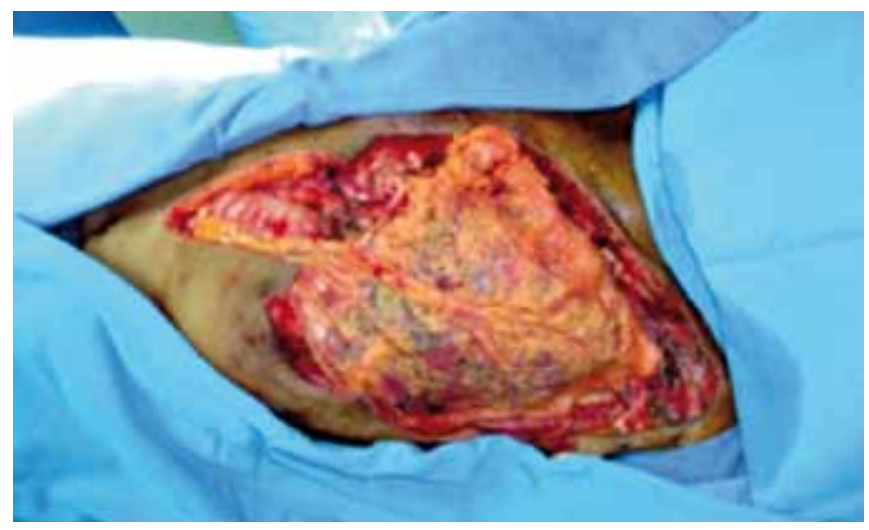

Figura 3 - Caso 1: Cobertura do defeito com o retalho. Preparação do leito receptor para enxertia de pele. 


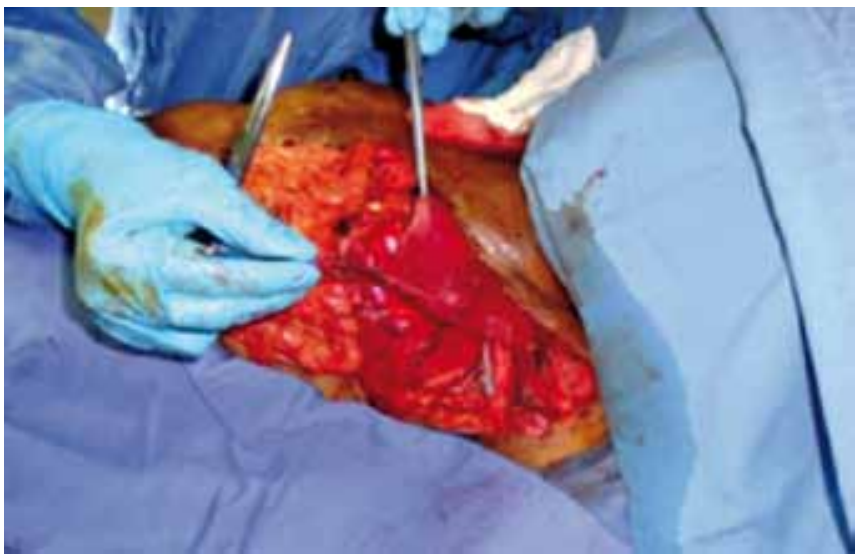

Figura 4-Caso 1: Retalho do pequeno peitoral cobrindo os vasos axilares.

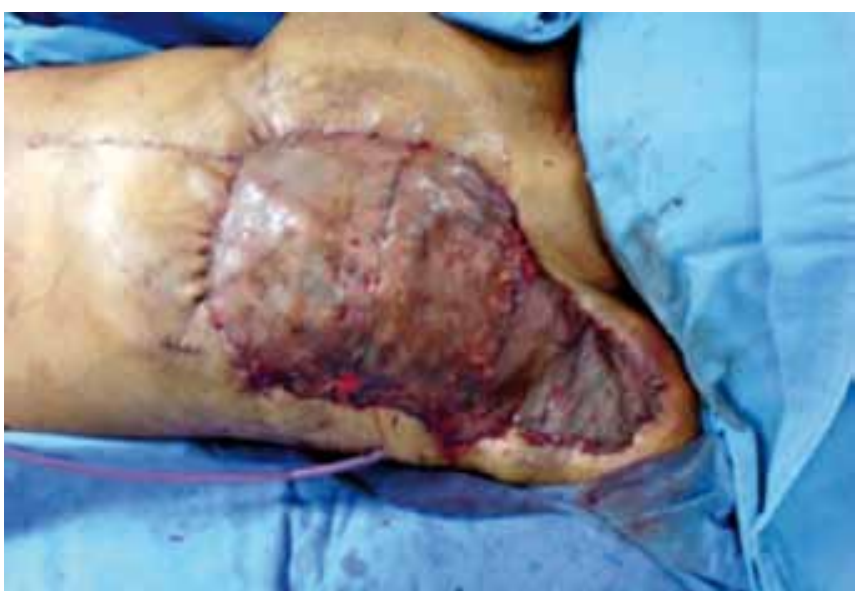

Figura 5-Caso 1: Aspecto final da cirurgia após fixação do omento e enxerto.

carcinoma intraductal. Submetida à mastectomia subcutânea bilateral e reconstrução bilateral com prótese.

Decorrido dois anos, a paciente apresentou intercorrências na mama esquerda: deiscência, necrose e extrusão de prótese. Foi, então, submetida a várias tentativas de reconstrução: retalhos locais, retalho do grande dorsal, todas sem sucesso. Por último, foi empregado retalho do músculo reto abdominal, porém após três anos da cirurgia a paciente apresentou recidiva em cicatriz cirúrgica. Realizada biópsia confirmando tumor filoide maligno e papiloma intraductal em área focal. Foi, então, proposta ressecção do sarcoma, abrangendo a área correspondente ao hemitórax esquerdo, $1 / 3$ superior do abdome esquerdo e região axilar esquerda. Reconstrução com epíplon vascularizado e enxerto de pele. Transcorridos quatro anos, a paciente não apresentou indícios de recidiva tumoral.

As Figuras 8 a 14 ilustram as principais etapas de atendimento dessa paciente.

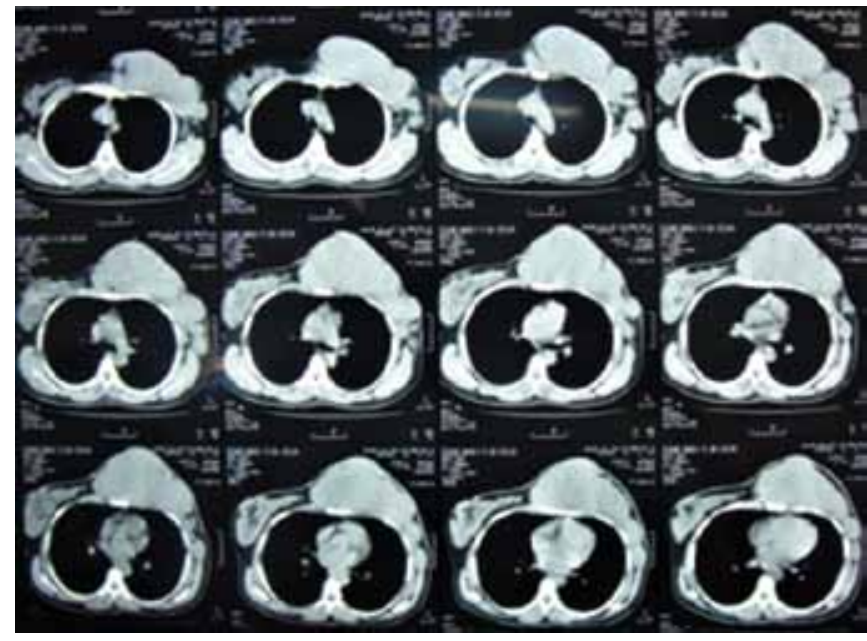

Figura 6-Caso 1: Tomografia pré-operatória.

Tumor ocupando todo o hemitórax esquerdo.

\section{DISCUSSÃO}

Na história da cirurgia reparadora do tórax, várias técnicas e variações destas têm sido descritas por diversos autores e em diferentes centros (retalhos musculares, microcirúrgicos, emprego de materiais aloplásticos, entre outros), de modo que o cirurgião dispõe de uma extensa gama de recursos para a execução destes procedimentos. Cada uma destas técnicas possui indicações e complicações razoavelmente bem estabelecidas na literatura. A escolha de cada uma delas obedece não só a critérios clínicos, como também a experiência do cirurgião e preferência pessoal deste e do paciente. Muitas vezes, essa decisão é tomada em conjunto, de forma multidisciplinar a depender de critérios clínico-oncológicos e extensão da ressecção a ser realizada. Muitas vezes, diferentes tipos de reconstruções podem ser feitos em casos similares. A princípio, quando o defeito da parede torácica atinge unicamente a pele $\mathrm{e}$ o tecido subcutâneo, qualquer método de cobertura poderá estar indicado, desde que obtenha tecido de cobertura suficientemente denso, com volume e qualidade adequados. Esse princípio básico se aplica a qualquer tipo de reconstrução, entretanto, as peculiaridades dos casos apresentados onde antes foram usados vários retalhos localmente possíveis e era necessário cobrir uma área grande, diminuiu bastante as possibilidades técnicas e mostrou o retalho de epíplon, pela excelente mobilidade e aporte circulatório inigualável, como uma boa opção.

Em nossa experiência, ambos os casos apresentaram resultado imediato bastante satisfatório. A evolução desfavorável de nossa primeira paciente nos mostra que, em casos de tumores localmente avançados, mesmo com ressecções completas, talvez haja alguma restrição ao uso deste retalho devido à vascularização intensa facilitar a disseminação tumoral. Devemse considerar também, em ambos os casos, a característica 


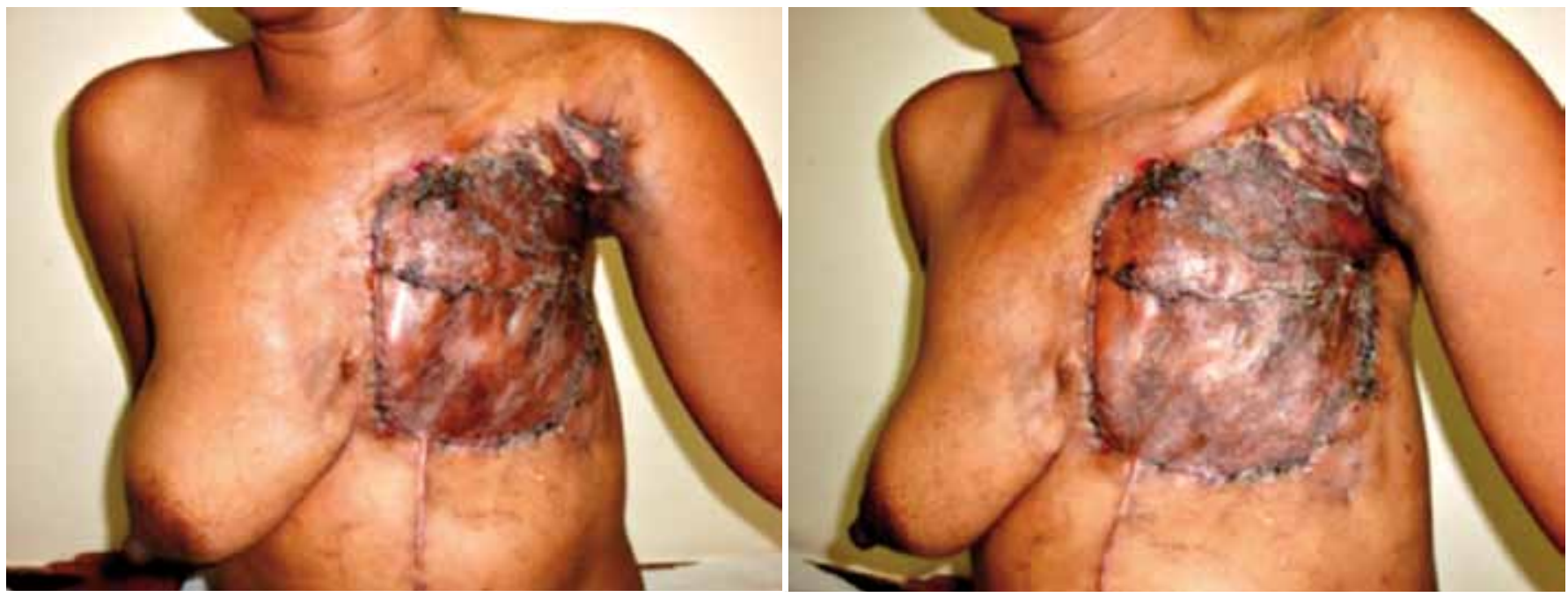

Figura 7 - Caso 1: Pós-operatório de trinta dias. Integração do enxerto e reparação do defeito.

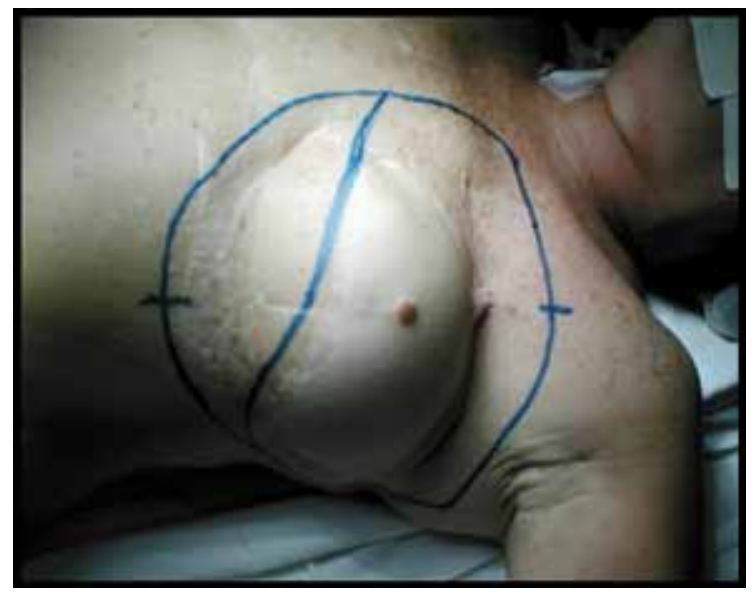

Figura 8 -Caso 2: Local da recidiva tumoral em cicatriz TRAM.

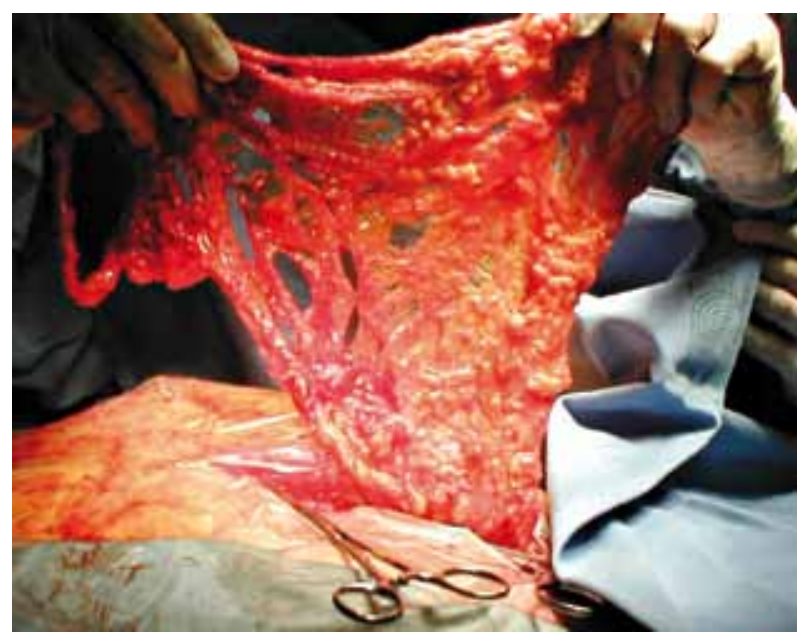

Figura 9 - Caso 2: Rotação do epíplon.

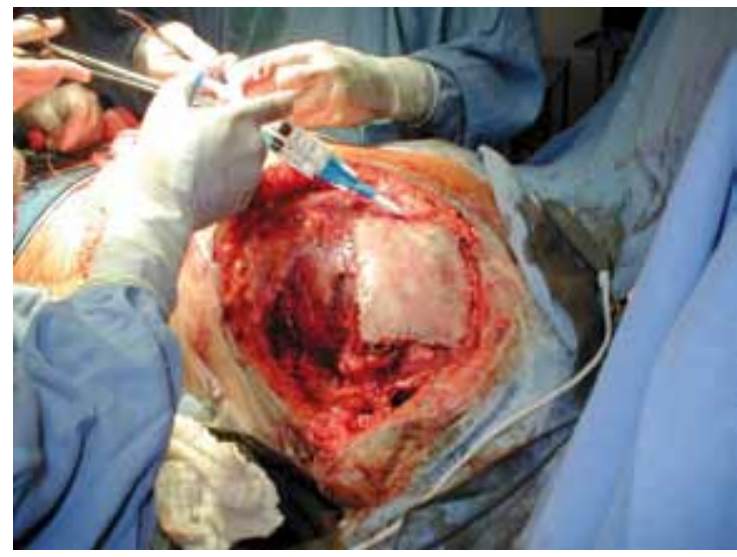

Figura 10 - Caso 2: Cobertura de defeito em parede torácica com pericárdio bovino e cola de fibrina.

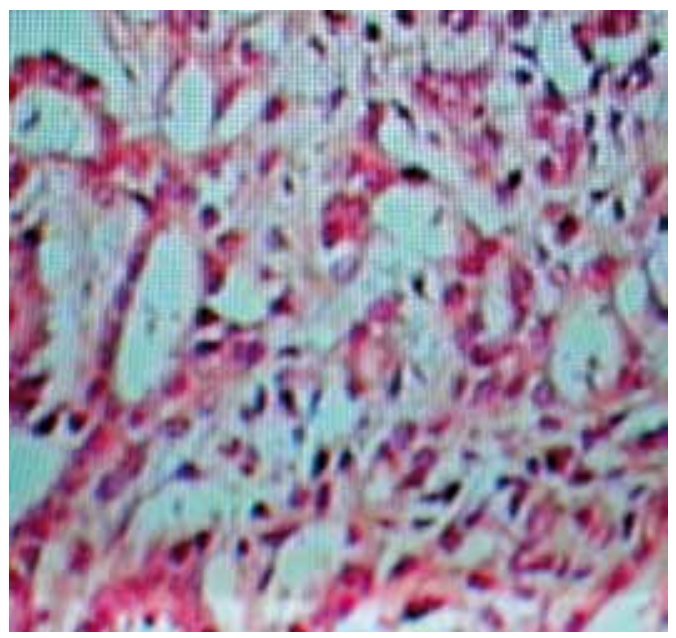

Figura 11 - Caso 2: Histopatológico: alta celularidade com atipias. 


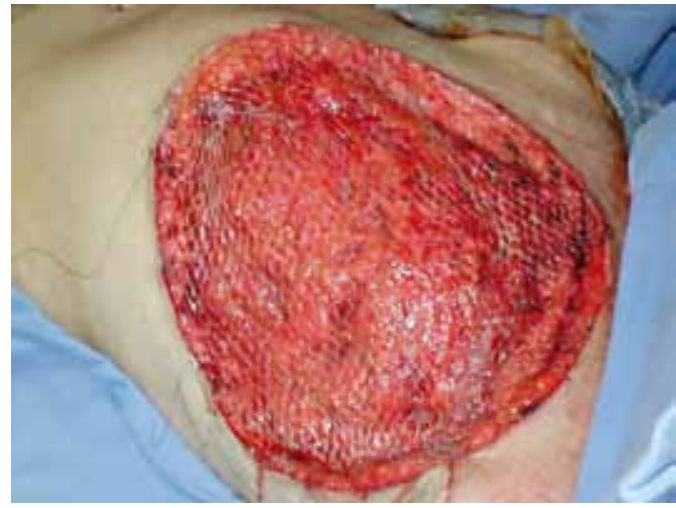

Figura 12 - Caso 2: Enxertia cutânea expandida.

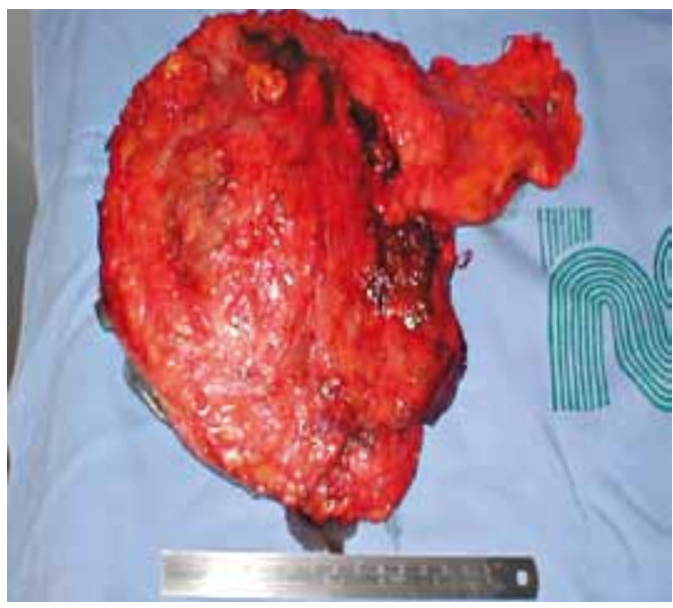

Figura 13 - Caso 2: Peça operatória.

extremamente agressiva e a história natural dos tumores filoides malignos. Observamos, ainda, que houve certa confusão no diagnóstico histopatológico inicial, já que, nos dois casos, os nódulos foram identificados como fibroadenomas, fato relativamente comum na história dos tumores filoides, devido à semelhança microscópica existente entre eles.

Até o momento, não foi diagnosticada doença metastática sistêmica em nenhuma das pacientes. A literatura ainda carece de um maior número de casos relatados e estudos controlados sobre o emprego do epíplon na cobertura da parede torácica.

\section{CONCLUSÃO}

Em nossa experiência, a reconstrução com retalho omental após ressecções de tumores da parede torácica mostra-se uma

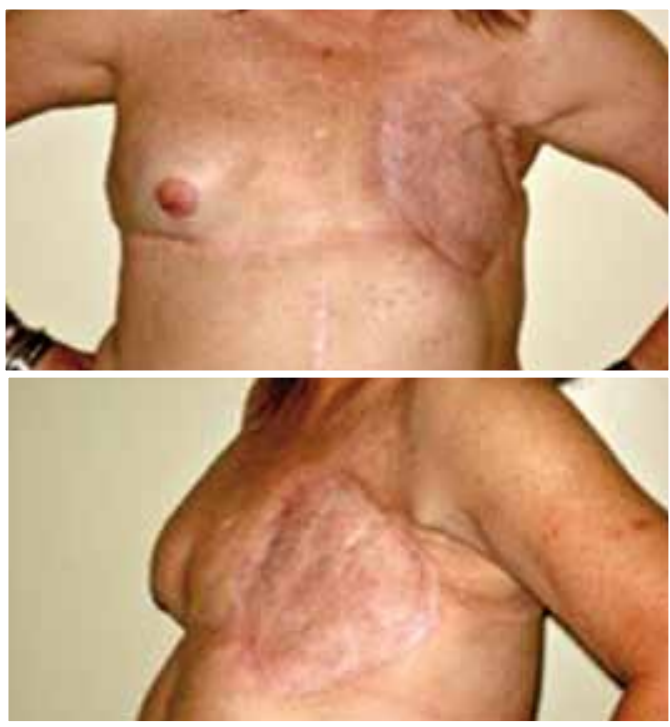

Figura 14 - Caso 2: Pós-operatório de quatro meses.

maneira eficaz, fácil e segura de cobertura do tórax, com um bom resultado funcional, porém esteticamente pobre. Aprendemos que podemos dar soluções relativamente simples para casos que nos pareçam complexos, e afirmando o retalho de epíplon como excelente opção para casos excepcionais.

\section{REFERÊNCIAS}

1. Drummond D, Morrison R. A case of ascites due to cirrhosis of the liver cured by operation. Br Med J. 1896,2:728.

2. Moor EV, Neuman RA, Weinberg A, Wexler MR. Transposition of the great omentum for infected sternotomy wounds in cardiac surgery. Report of 16 cases and review of published reports. Scand J Plast Reconstr Surg Hand Surg. 1999;33(1):25-9.

3. Goldsmith HS, De los Santos R. Omental transposition for the treatment of chronic lymphedema. Rev Surg. 1966;23(4):303-4.

4. Goldsmith HS, De los Santos R. Omental transposition in primary lymphedema. Surg Gynecol Obstet. 1967;125(3):607-10.

5. Góes J Sampaio, Macedo AV. Reconstrução imediata após mastectomia via periareolar com retalho de omento e tela mista. In: Mélega, JM, ed. Cirurgia Plástica Fundamentos e Arte. Cirurgia reparadora de tronco e membros. $1^{\mathrm{a}}$ ed. vol. 4. São Paulo:Medsi;2004. p.220-5.

6. Kiricuta I. Lémploi du grand épiploon dans la chirurgie du sein cancéraux. Press Med. 1963;71:15-7.

7. Casten DF, Alday ES. Omental transfer for revascularization of the extremities. Surg Gynecol Obstet. 1971;132(2):301-4.

8. Arnold PG, Pairolero PC. Reconstruction of the radiation-damage chest wall. Surg Clin North Am.1989;69(5):1081-9.

9. Alday ES, Goldsmith HS. Surgical technique for omental lengthening based on arterial anatomy. Surg Gynecol Obstet. 1972;135(1):103-7.

10. Sittig KM, Rohr MS, McDonald J. Parede abdominal, omento, mesentério e retroperitônio. In: Sabiston CD, Lyerli HK, eds. Tratado de cirurgia. $18^{\mathrm{a}}$ ed. Rio de Janeiro:Guanabara Koogan, 1999. p.852-3. 